\title{
V Kipupa Malunguinho da Jurema Sagrada
}

\author{
L Pedro Stoeckli Pires
}

\begin{abstract}
A jurema (Acacia Nigra) é uma planta e culto presente em diversas variaçóes religiosas, tais como o catimbó e a umbanda. Entre suas principais características está a tomada do corpo por entidades espirituais como mestres e caboclos. Sua tradição vem de origens indígenas e sua difusão se deu juntamente com o estabelecimento de outras práticas e religióes, como a umbanda. Das raízes e cascas da planta é produzida uma bebida, o vinho da jurema, que é consumido ritualmente durante o culto.
\end{abstract}

Nesse ensaio retrato o V Kipupa Malunguinho Coco na Mata, encontro de juremeiros na mata do Catucá, ocorrido no dia 19 de setembro de 2010. O encontro, organizado pelo Quilombo Cultural Malunguinho, chegou ao seu quinto ano com o objetivo de "homenagear e reconhecer Malunguinho, líder negro que elevou-se à divindade na jurema assumindo a patente de Rei da Jurema, se firmando na tradição oral e teológica nordestina como defensor espiritual", como os próprios organizadores o definem.

$\mathrm{Na}$ jurema há uma forte ênfase na aproximação com a mata e com o pé da planta jurema. Mesmo que a mata seja ainda a fonte do poder e mística da jurema, os trabalhos nesses locais são cada vez mais difíceis e esparsos. Isso se dá claramente pelas dificuldades práticas que a crescente urbanizaçáo oferece, dentre elas a de encontrar espaços dentro da cidade onde a planta possa ser cultivada e mantida. Dessa forma, encontros como o Kipupa são ocasiôes em que vários juremeiros podem realizar seus trabalhos e oferendas na mata, o que é muito valorizado. Neste dia, juremeiros se reuniram para cantar, dançar e homenagear Malunguinho e outras entidades da jurema.

A dinâmica do encontro funcionou como uma grande festa. A sequência das imagens desse ensaio mostra as oferendas sendo colocadas no altar dedicado a Malunguinho, o processo 
I92 | Pedro Stoeckli Pires

de abençoá-las através da fumaça e as giras dos mestres da jurema. Em seu contexto ritual, as danças, as saudaçóes, as oferendas e a manipulação de objetos sagrados apresentam aspectos que são dificilmente compreendidos pela descrição textual. É nessa fronteira que a fotografia e a narrativa imagética se mostram importantes instrumentos durante o trabalho de campo.

\section{autor Pedro Stoeckli Pires}

Doutorando em Antropologia Social / PPGAS - UnB

Recebido em 28/05/2012

Aceito para publicação em 30/08/2012 
V Kipupa Malunguinho da Jurema Sagrada | i 93

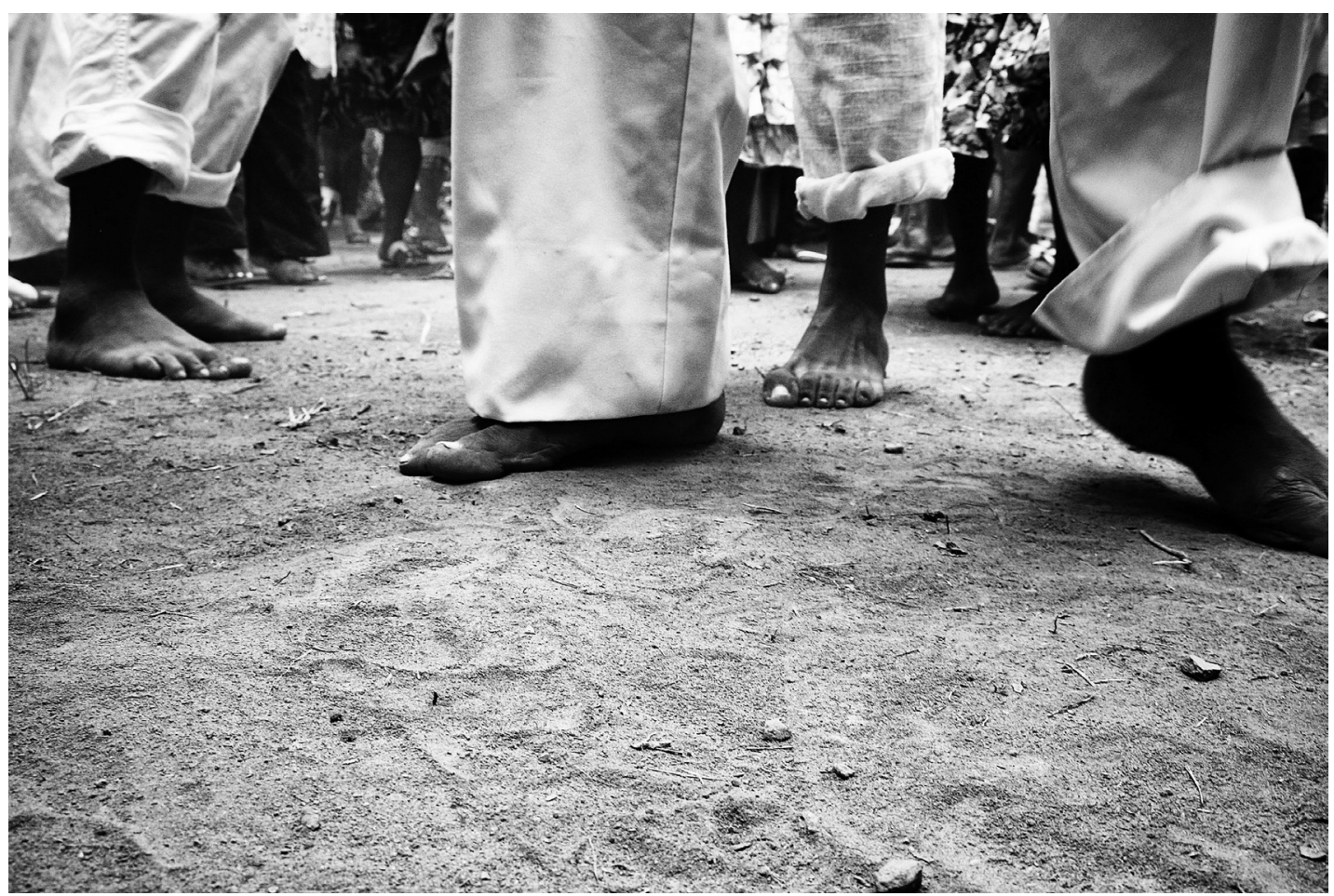

1. Detalhe dos pés descalços dos juremeiros em contato com a terra.
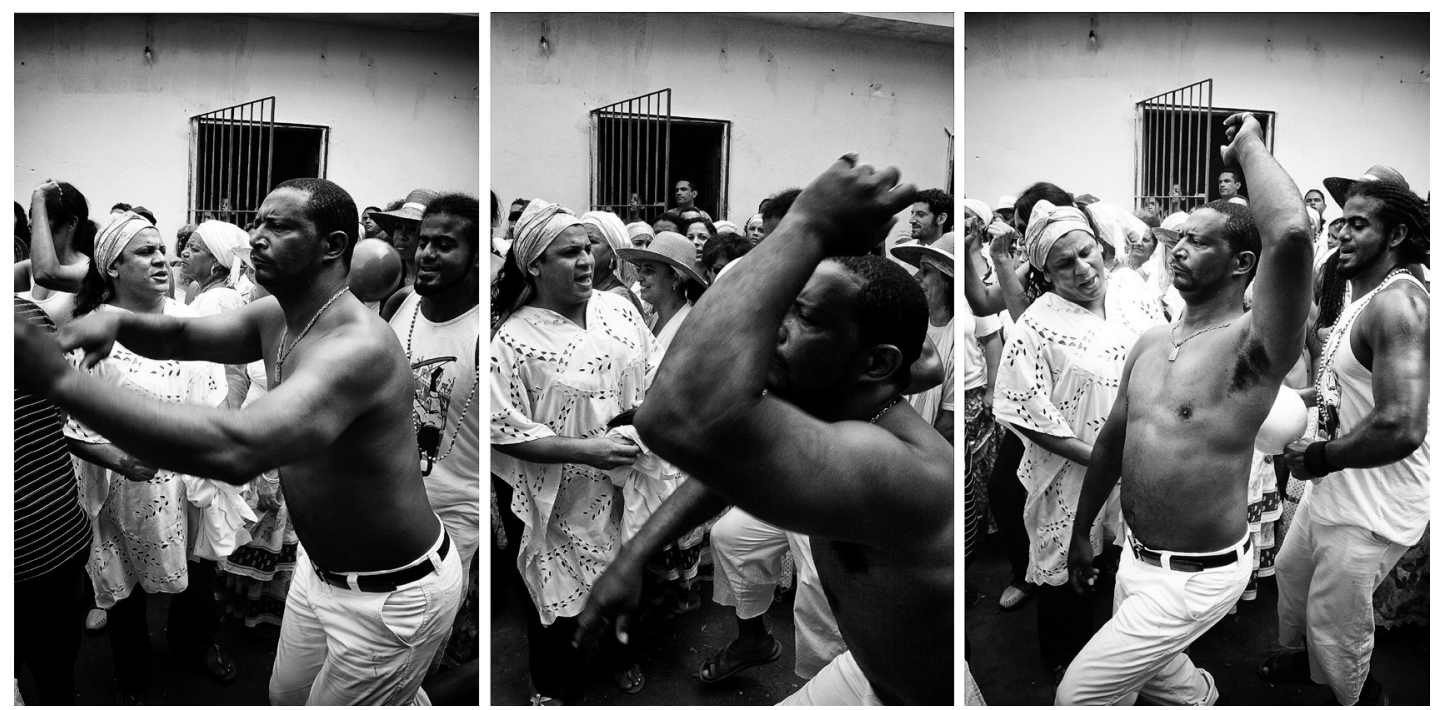

2. Sequência de imagens demonstrando a dança de uma entidade Malunguinho com seus típicos movimentos de braços e corpo. 
i 94 | Pedro Stoeckli Pires

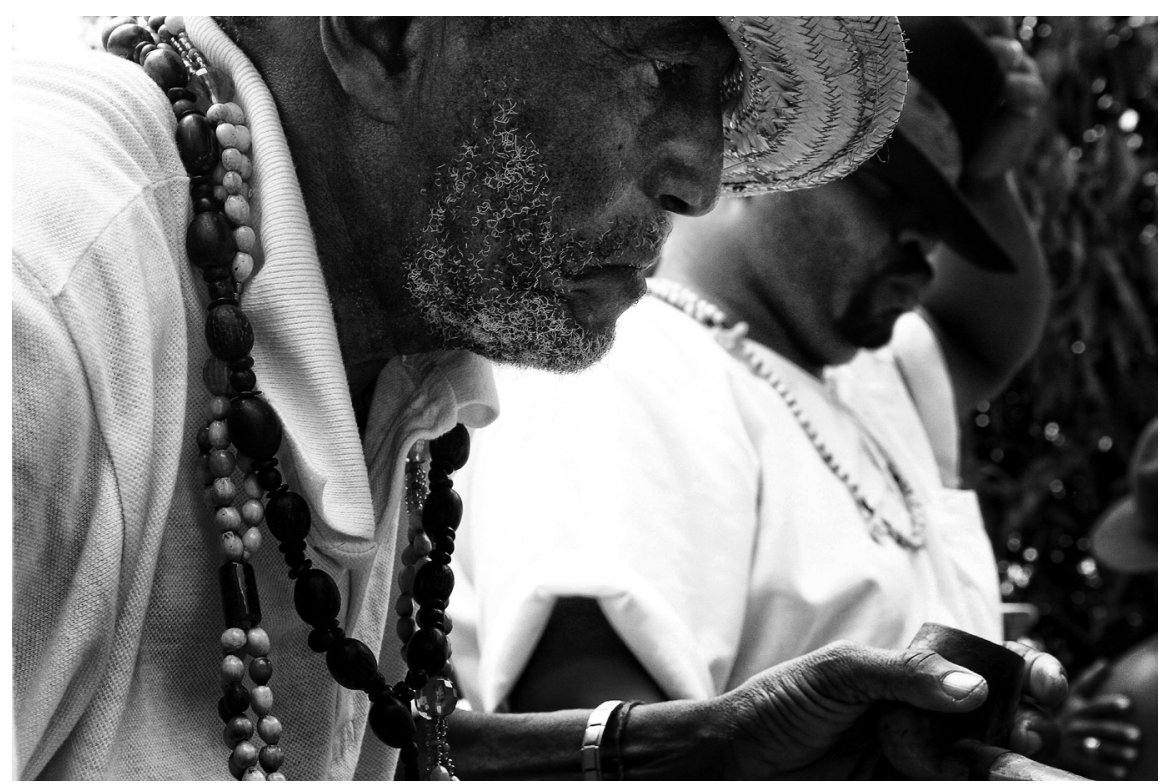

3.Dois juremeiros incorporam entidades da jurema. 0 chapéu, as guias e os cachimbos são elementos bastante presentes nas cerimônias.

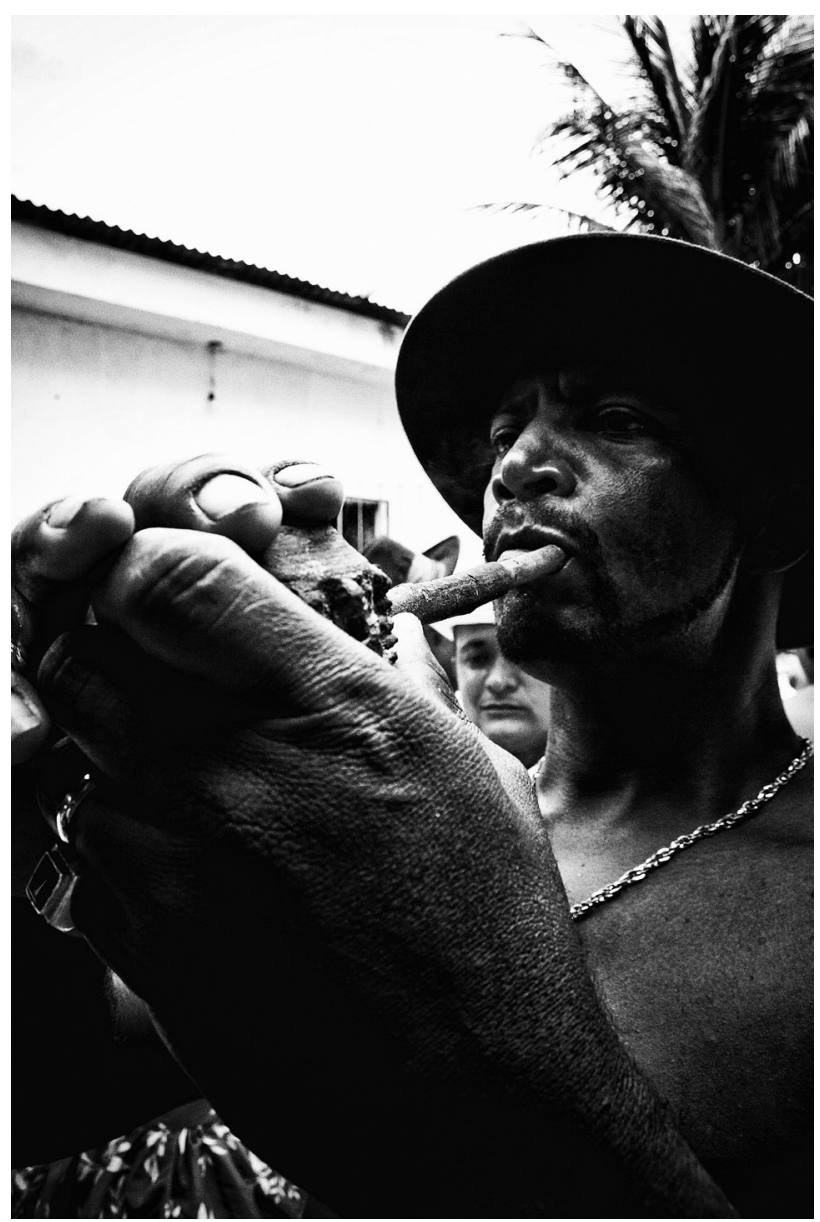

4. Uma entidade Malunguinho prepara seu charuto para jogar a fumaça sagrada para 0 alto. 


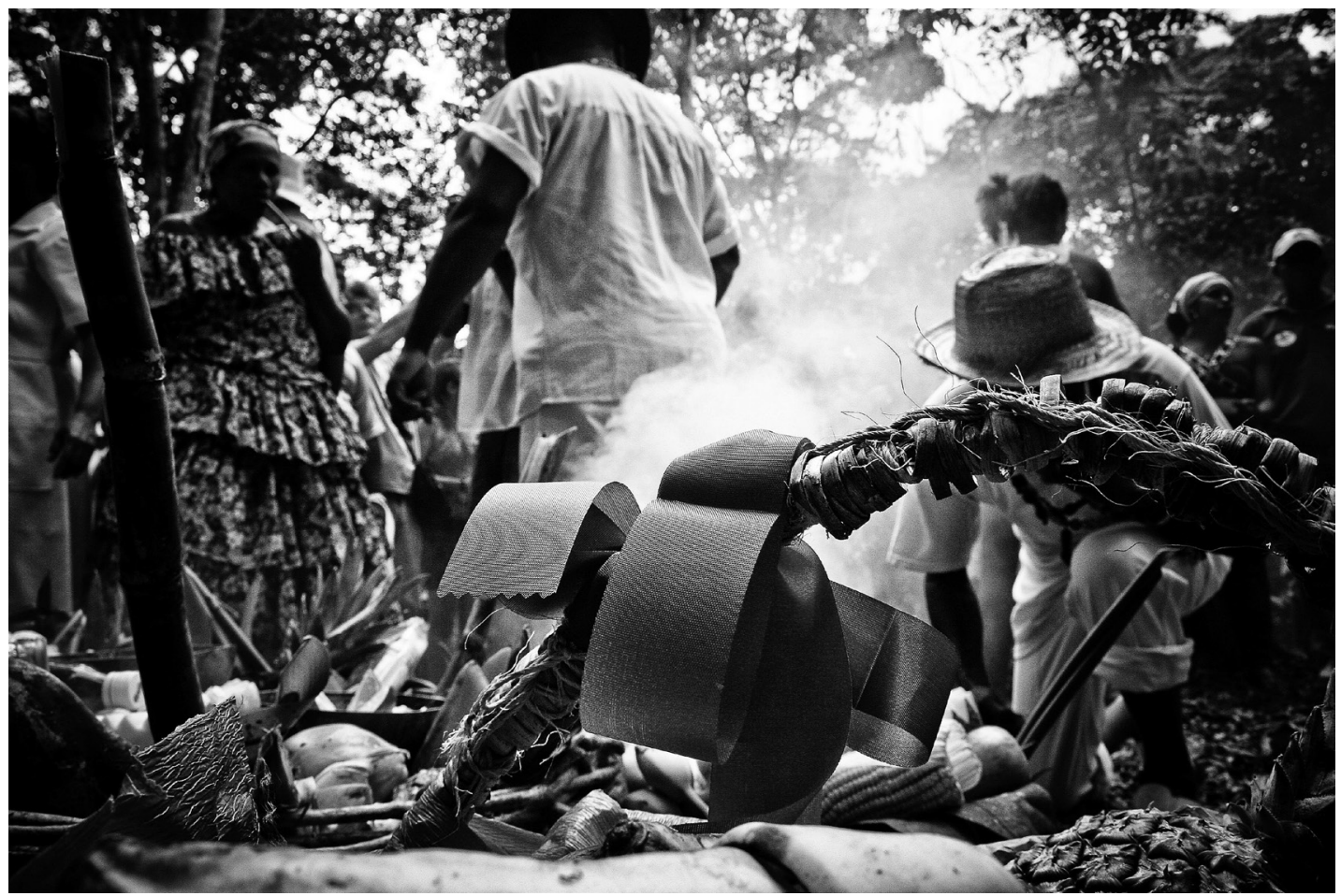

5. As cestas com oferendas de frutas e os defumadores são arranjados na mata como altares. No detalhe, duas fitas com as cores de Malunguinho.

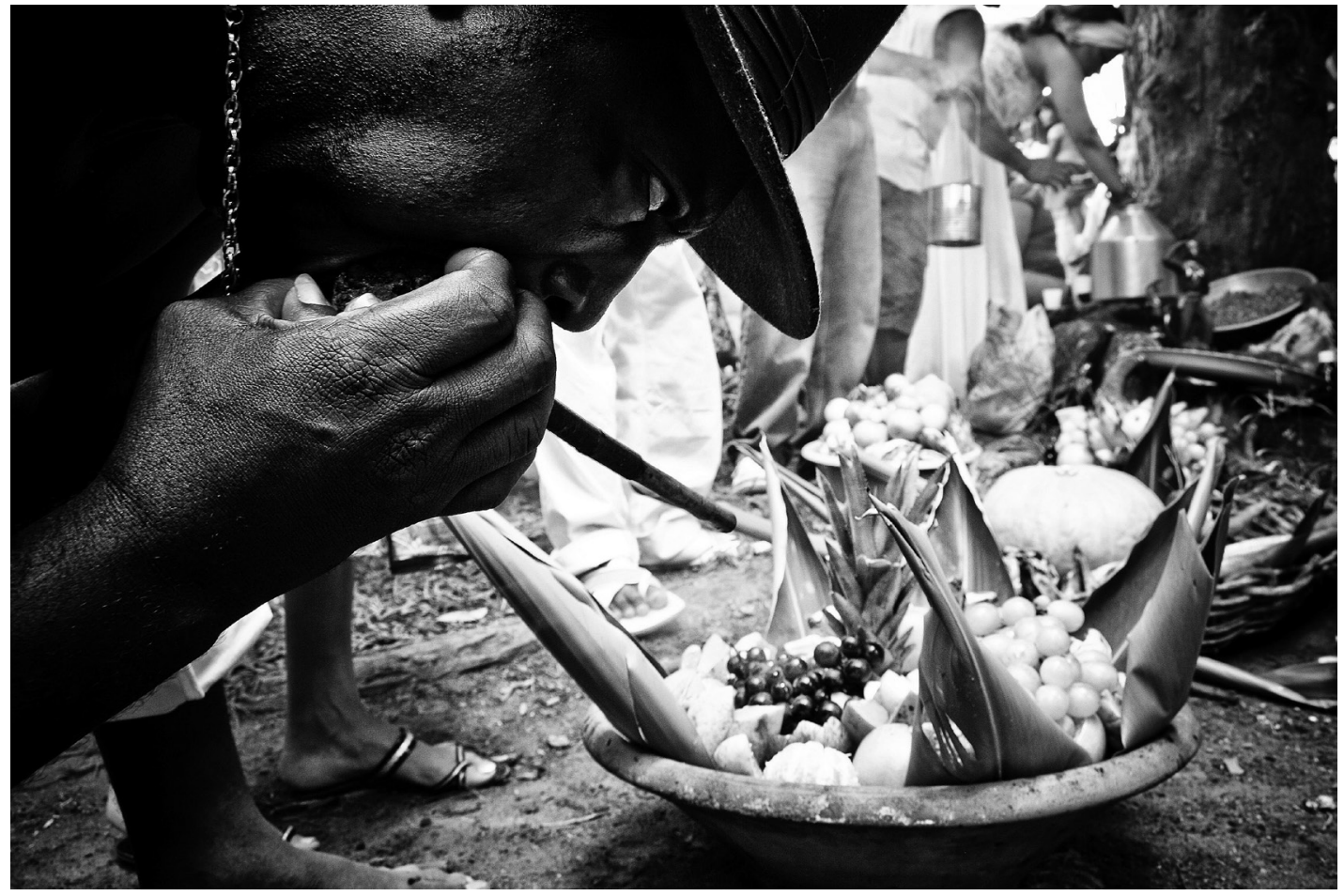

6. Uma entidade Malunguinho joga sua fumaça na cesta de oferendas benzendo-a. 
i96 | Pedro Stoeckit Pires

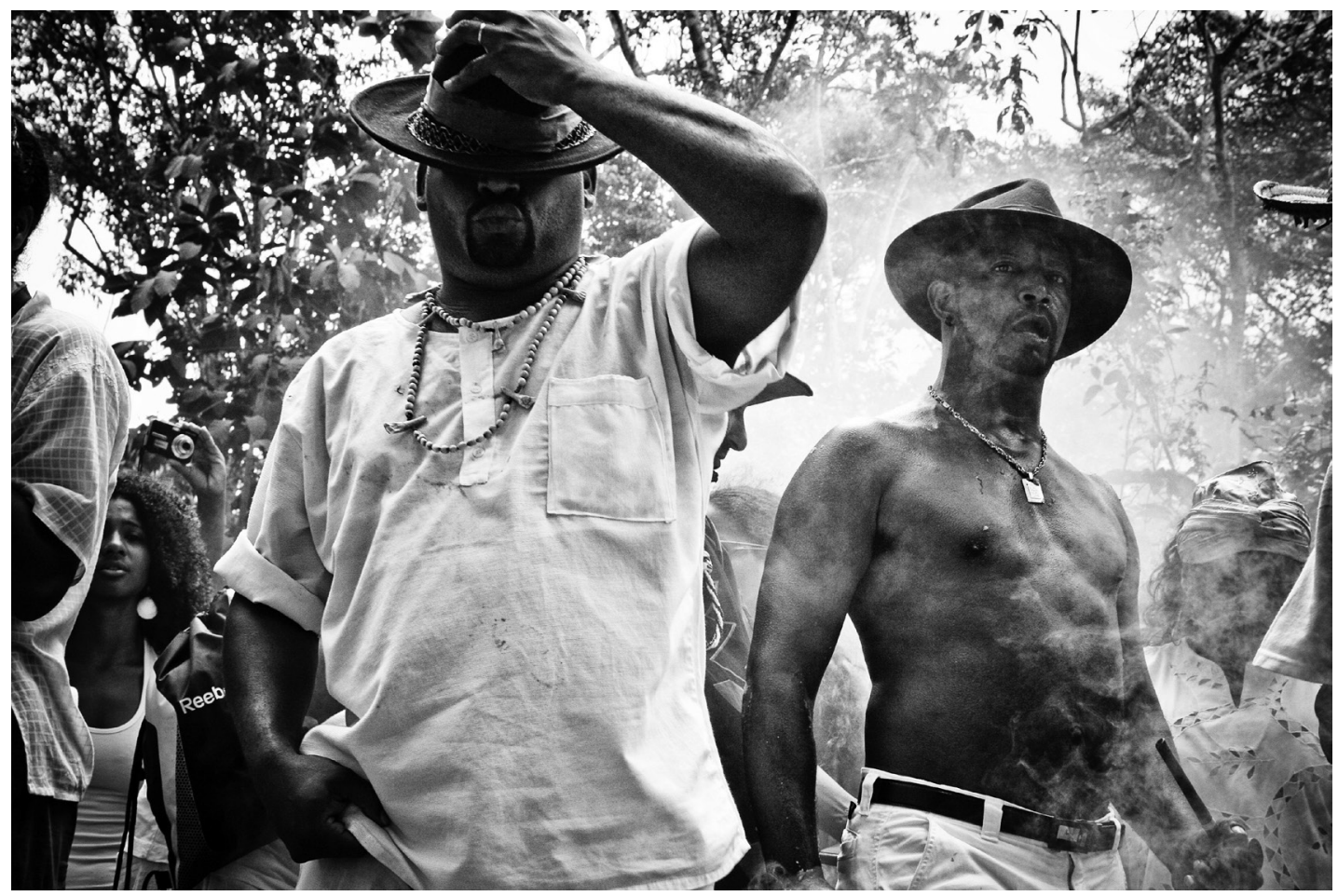

7. Dois mestres da jurema envoltos pela fumaça dos defumadores e dos cachimbos.

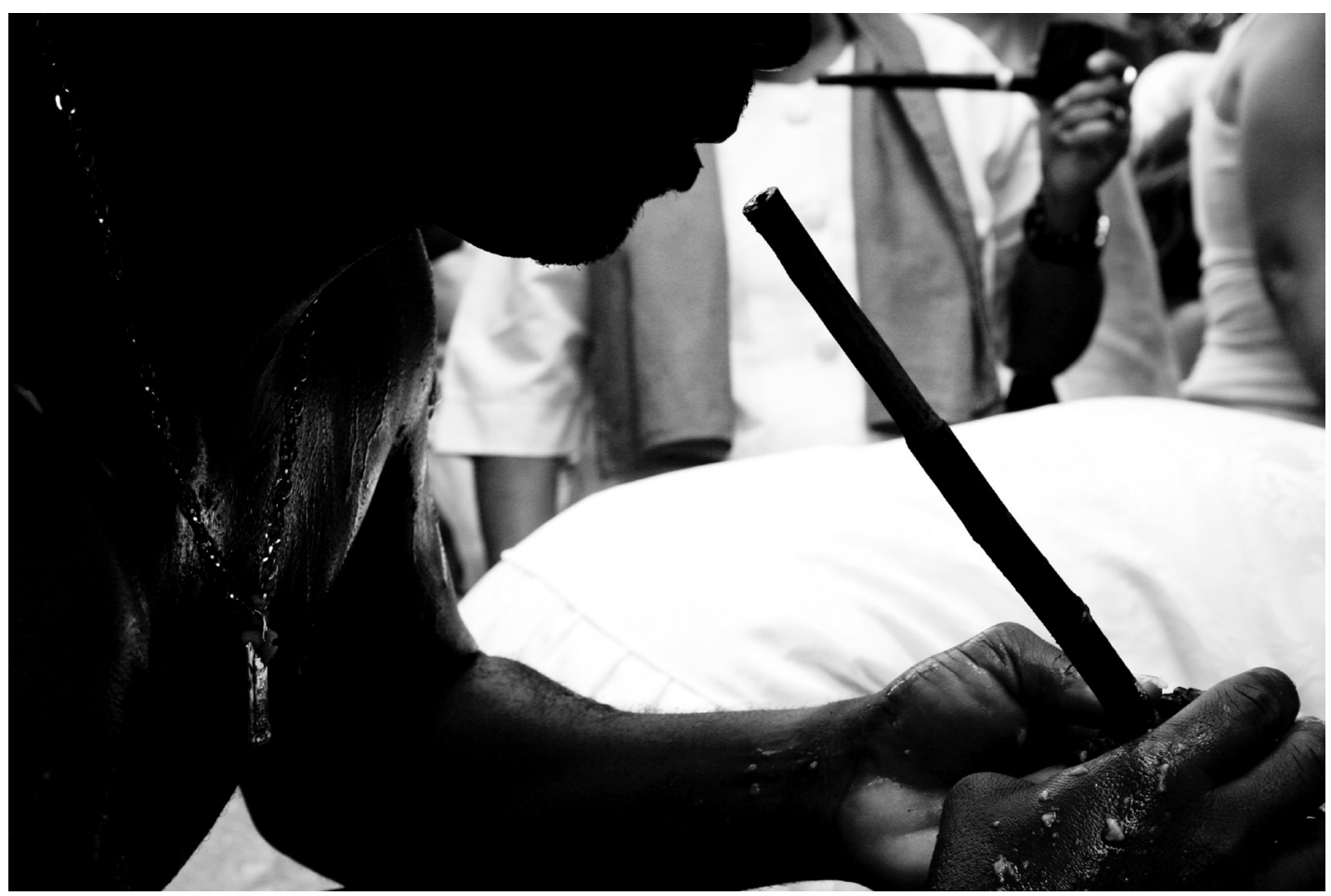

8. Um Malunguinho com seu cachimbo na contra-luz. 